\title{
The fate of $\mathrm{CaCO}_{3}$ in Earth's subduction zones
}

\author{
YingweI FeI', JiNG YANG ${ }^{1}$, AMANDA LINDOO ${ }^{12}$, \\ RENBIAO TAO ${ }^{13}$
}

${ }^{1}$ Carnegie Institution for Science, 5251 Broad Branch Road, NW, Washington DC 20015, USA.

yfei@carnegiescience.edu

${ }^{2}$ Now at School of Earth Sciences, University of Bristol, UK

${ }^{3}$ Now at School of Earth and Space Sciences, Peking

University, China

Calcium carbonate $\left(\mathrm{CaCO}_{3}\right)$ is an important component of the subducted oceanic crust, transporting carbon from the surface into deep Earth's interior and returning it back via volcanic or/and tectonic processes. In this study, we conducted a series of experiments aimed to understand the stability and mobility of in subducting slabs from the upper mantle to the top of the lower mantle conditions. In the experiments composed of and olivine- $\mathrm{CaCO}_{3}$ mixture at 3.5-6.5 GPa and $850-1630^{\circ} \mathrm{C}$, we observed a distinct texture change from a granular to melt-like texture at about $1130^{\circ} \mathrm{C}$. The temperature associated with the texture change is far below the melting temperature of $\mathrm{CaCO}_{3}$, but consistent with our recent report of temperature-induced amorphization in $\mathrm{CaCO}_{3}$ [1]. The observed small wetting angles (siginificantly below the critical angle of $60^{\circ}$ ) of the amorphous $\mathrm{CaCO}_{3}$ indicate it should readily form an interconnected network within a solid matrix. We have also examined the interaction of $\mathrm{CaCO}_{3}$ with $\mathrm{Fe}^{2+}$-garnet and observed similar texture change in $\mathrm{CaCO}_{3}$ at $1200^{\circ} \mathrm{C}$ and 8 $\mathrm{GPa}$. In addition, we demonstrated a redox reaction between $\mathrm{Fe}^{2+}$-garnet and $\mathrm{Ca}$-carbonate to produce oxidized $\mathrm{Fe}^{3+}$ rich garnet and reduced carbon (graphite or diamond). Under experimental conditions corresponding to the top of the lower mantle up to $30 \mathrm{GPa}$, we observed direct formation of $\mathrm{CaSiO}_{3}$ perovskite by reaction of $\mathrm{CaCO}_{3}$ and $\mathrm{SiO}_{2}$-stishovite. The released $\mathrm{CO}_{2}$ forms diamond under a reduced environment. The results from these experiments demonstrate that $\mathrm{Ca}-$ carbonate in the subduction environment may be easily mobile and rheologically weak as amorphous $\mathrm{CaCO}_{3}$. Furthermore, it could be an unrecognized $\mathrm{CO}_{2}$ source for arc volcanism and a key agent for the redox reaction to form deep diamonds.

[1] Hou, M., Zhang, Q., Tao, R., Liu, H., Kono, Y., Mao, H. K., Yang, W., Chen, B., \& Fei, Y. (2019) Nature comm., 10(1), $1-8$. 